\title{
Thermoperiodic effects on diapause of Sesamia nonagrioides (Lepidoptera: Noctuidae)
}

\author{
Argyro A. FANTINOU*, Costas S. CHATZOGLOU and Elena A. KAGKOU \\ Laboratory of Ecology and Environmental Sciences, Agricultural University of Athens, Iera Odos 75, Athens 11855, Greece; \\ e-mail: Argyr@aua.gr
}

Key words. Sesamia nonagrioides, diapause induction, development, thermoperiod, thermophotoperiod

\begin{abstract}
The role of the thermophotoperiod on larval diapause induction and development of Sesamia nonagrioides was investigated under laboratory conditions. The incidences of diapause by TC $12: 12$ thermoperiods under DD, in which the thermophase was $30^{\circ} \mathrm{C}$ and cryophases varied from 10 to $25^{\circ} \mathrm{C}$, were compared to the effects of thermophotoperiods with the same configuration. Higher incidences of diapause were recorded when larvae were exposed to thermophotoperiods with cryophases of $15-25^{\circ} \mathrm{C}$, than under thermoperiods under constant darkness. In addition, larvae exhibited significantly lower percentages of diapause when exposed to cryophases $<15^{\circ} \mathrm{C}$ under either thermo- or thermophotoperiodic condition. Diapausing larvae when exposed to photoperiods $16 \mathrm{~L}: 8 \mathrm{D} \mathrm{h}$ and different temperatures of $25-30^{\circ} \mathrm{C}$ proceeded to development in $14-16$ days. Moreover time needed for the pupation of diapausing larvae after their transfer to $12 \mathrm{~L}: 12 \mathrm{D} \mathrm{h}$, was reduced from approximately 49 to 12 days depending on temperatures of exposures $\left(25-30^{\circ} \mathrm{C}\right)$. Diapause termination was also compared under $12 \mathrm{~L}: 12 \mathrm{D} \mathrm{h}$ and constant temperature of $25^{\circ} \mathrm{C}$ or a thermoperiod of TC $12: 12\left(30^{\circ}: 20^{\circ}\right)$. Days needed for pupation at constant temperature or under the mentioned thermoperiodic regime, were approximately the same when the high temperature of the thermoperiod coincided with the scotophase, while with the co-occurrence of the high temperature of the thermoperiod and the photophase significantly additional time was needed for diapause development. Significantly shorter time was also needed for diapause development after exposure of diapausing larvae to continuous light, than to continuous darkness under $25^{\circ} \mathrm{C}$. Thermoperiods of different amplitudes with the same mean temperatures proved that the higher temperature of scotophase led to higher rate of diapause development in spite of the relatively low temperature of the photophase tested. It is suggested that thermoperiod could hasten the time needed for diapause development, but it is not the crucial factor for the termination of diapause.
\end{abstract}

\section{INTRODUCTION}

The influence of thermoperiod on insect growth, development and behaviour has been well documented in recent years. Complex thermoperiod - photoperiod interactions have been observed on seasonal biology in several insects and various studies have been published on the effect of artificial daily temperature cycles on insect behaviour, e.g. development and cold tolerance (Spodoptera exigua Hubner; Kim \& Song, 2000), oviposition (Atrachya menetriesi Feldermann; Yamashiro et al., 1998), eclosion rhythms (Trichogramma evanescens Westw.; Zaslavski et al., 1995), or diapause (Ostrinia nubilalis Hubner; Beck, 1982; Pyrrhocoris apterus L.; Kalushkov et al., 2000; Bruchidius atrolineatus Pic; Lenga \& Huignard, 1992; Microplitis croceipes Cresson; Brown \& Philips, 1991).

The need for extensive research into the thermoperiodic influences on seasonal behavior of insects may be important from an ecological and phenological standpoint in temperate regions. One problem encountered in the study of a thermoperiod is its coincidence (or non-coincidence) with a concurrent photoperiod. This reveals further problems arising from the alteration of the mean temperature between different thermophotoperiodic regimes. For this reason, most such studies deal with photoperiods of $12 \mathrm{~L}$ :
12D, or take place under continuous darkness (DD) or light (LL).

The stalk borer Sesamia nonagrioides (Lefebvre) (Lepidoptera: Noctuidae), a multivoltine species, causes noticeable damage on maize boring galleries in the stem, throughout the Mediterranean basin (Leclant, 1976; Galichet, 1982; Cordero et al., 1998). This species overwinters as a mature larva and in Greece the first adults appear from early March to early May, in mild and cold areas, respectively (Tsitsipis, 1990; Fantinou et al., 1995). During diapause larvae continue to feed, undergoing supernumerary moults (Fantinou et al., 1996).

Photoperiod has been reported as the major factor controlling the induction and termination of larval diapause under laboratory conditions, while temperature could influence the response to daylength (Hilal, 1977; Eizaguirre et al., 1994; Fantinou et al., 1995). According to Galichet (1982) this species exhibits an oligopause (see for definition Mueller, 1970) and a temperature of $25^{\circ} \mathrm{C}$ is effective in hastening diapause development under both long and short-days.

In a recent study, Fantinou \& Kagou (2000) examined the effect of thermoperiod on diapause induction of this species and suggested that the photoperiodic induction of larval diapause was enhanced by superimposed thermoperiods, particularly when the low temperature coincided

\footnotetext{
* Corresponding author. Tel.: (+301) 5294 404; fax: (+301) 5294462
} 


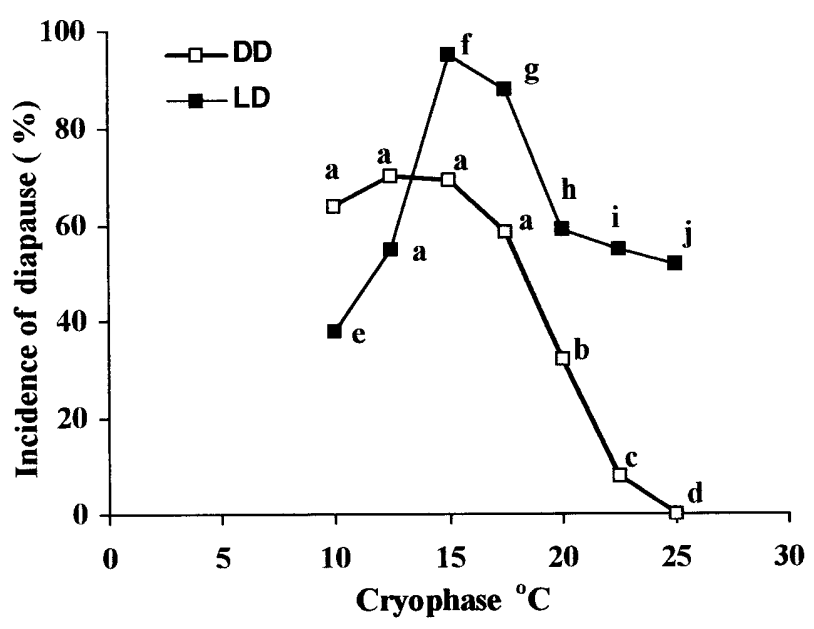

Fig. 1. Diapause incidence (\%) in $S$. nonagrioides larvae reared under thermoperiodic (TC $12: 12$ ) at DD and thermophotoperiodic $(12 \mathrm{~L}: 12 \mathrm{D} \mathrm{h})$ conditions by regimes with different cryophase and cryoscotophase temperatures and a thermophase of $30^{\circ} \mathrm{C}$.

Each symbol shows the mean value of 4 replicates of 25 larvae each.

Values labeled with the same letter are not significantly different at $P=0.05$ by LSD test after ANOVA.

with the scotophase. Moreover, thermoperiod per se could induce diapause, whereas both the duration and the temperature of the cryophase were important factors controlling the diapause response.

In the current study, we attempt to determine the interacting effects of thermoperiod and photoperiod controlling induction, as well as the termination of diapause and the ecological significance of the different thermoperiods on the diapause development of this species.

\section{MATERIALS AND METHODS}

A laboratory colony of the stalk borer, originating from larvae field-collected in 1999 in Kopais, central Greece and kept on artificial diet (Tsitsipis, 1984) for $2 \mathrm{yr}$, was used in all our experiments. Maintenance and handling of the colony has been described (Fantinou et al., 1995). Larvae were considered diapausing when they did not reach at $25^{\circ} \mathrm{C}$ larval-pupal ecdysis by the age of $55 \mathrm{~d}$ from egg hatch (Fantinou et al., 1995).

Experiments were carried out in small incubators providing either constant or changing temperatures and any photoperiodic regime by daylight fluorescent lamps $(8 \mathrm{~W})$. Reported temperatures were accurate to within $\pm 1^{\circ} \mathrm{C}$, while the transition from one temperature to another was complete within ca $30 \mathrm{~min}$ after switching. Observations under DD were made using red light, provided by a combination of red and orange plastic filters allowing light transmission at a wavelength longer than $540 \mathrm{~nm}$. Larvae were kept on artificial diet, which was changed weekly. Four replicates of 25 larvae were used per treatment.

To investigate the different effects of cryophase and cryoscotophase temperatures on the incidence of diapause in $S$. nonagrioides, neonate larvae less than $24 \mathrm{~h}$ old were exposed either to constant darkness and a thermoperiod (Thermophase: Cryophase) TC $12: 12$ in which the thermophase was $30^{\circ} \mathrm{C}$ and cryophases varied from 10 to $25^{\circ} \mathrm{C}$, or to a thermophotoperiod with the same configuration.

The effect of constant temperatures $\left(25,27.5\right.$ and $\left.30^{\circ} \mathrm{C}\right)$ on diapause development was evaluated by rearing $55 \mathrm{~d}$ old dia- pausing larvae under different photoperiodic regimes (LD $10: 14,12: 12$ or $16: 8 \mathrm{~h}$ ). The involvement of thermoperiod on diapause development was examined by measuring the time needed for the pupation of diapausing larvae after their transfer to different thermoperiodic treatments TC $12: 12\left(25^{\circ}: 25^{\circ}, 30^{\circ}\right.$ : $20^{\circ}$ or CT $20^{\circ}: 30^{\circ}$ ), and light conditions such as LD 12: $12 \mathrm{~h}$, constant light (LL) or constant darkness (DD). Moreover, the role of temperature cycles of different amplitude was determined by comparing TC $12: 12\left(26^{\circ}: 24^{\circ}, 28^{\circ}: 22^{\circ}, 30^{\circ}: 20^{\circ}\right.$, $32^{\circ}: 18^{\circ}$ and $34^{\circ}: 16^{\circ}$ ), under a photoperiod of $12 \mathrm{~L}: 12 \mathrm{D} \mathrm{h}$. Each regime therefore, had a mean temperature of $25^{\circ} \mathrm{C}$ and a symmetrical thermoperiod of two $12 \mathrm{~h}$ phases. Pupation was recorded daily in each treatment. Data were analyzed by using the procedures of a statistical programme provided by Statistical Graphics (1991). Data on diapause incidence (\%) were transformed using an arcsine square-root transformation before ANOVAs were conducted. The diapause response and days needed for pupation between treatments were analysed with analysis of variance (ANOVA); means were separated by least significant difference test (LSD) $(p<0.05)$.

\section{RESULTS}

The effect of different cryophase and cryoscotophase temperatures on diapause incidence in $S$. nonagrioides is shown in Fig. 1. The presence of the photoperiod 12L : $12 \mathrm{D}$ (which was the difference between the two treatments) revealed quite great differences in insect response, although there was a similarity in curves representing the two treatments. A negative correlation of the incidence of diapause with the increase of the temperature of the cryophase was also evident, as the temperature rises from 15 to $25^{\circ} \mathrm{C}$, whereas lower percentages of diapause appeared at very low cryophase temperatures, such as $10^{\circ} \mathrm{C}$, under both lighting treatments. Moreover, significantly higher percentages of diapause occurred under LD compared with constant darkness when cryophase temperatures were greater than $15^{\circ} \mathrm{C}$ (Fig. 1 and Table 1).

The effect of constant temperatures on different photoperiodic regimes on diapause development was compared (Table 2). The progress of diapause development is expressed in days needed for the $50 \%$ of pupation of larvae. Photoperiod had a definite effect on diapause termination in $S$. nonagrioides. Time needed for the pupation of larvae was considerably reduced when larvae were transferred to $16 \mathrm{~L}: 8 \mathrm{D}$ or $12: 12 \mathrm{~h}$, compared with those remained under the diapause promoting photoperiod $(10 \mathrm{~L}$ : $14 \mathrm{D} \mathrm{h}$ ) at $25^{\circ} \mathrm{C}$. The data also show that diapause development was enhanced at $27.5^{\circ} \mathrm{C}$ in all photoperiodic regimes tested. A further great reduction of the time needed for pupation resulted from a relatively small increase in temperature (from 27.5 to $30^{\circ} \mathrm{C}$ ), and no significant differences in time occurred in the photoperiods tested (Table 1 and 2).

Table 3 shows the effect of a thermoperiod of TC 12:12 $\left(30^{\circ}: 20^{\circ}\right)$ combined with a photoperiod of $12 \mathrm{~L}: 12 \mathrm{D} \mathrm{h}$, continuous illumination LL or darkness DD on the termination of diapause. Thermoperiod did not have a decisive role in reducing the time needed for the diapause completion (Table 2 and 3). Under 12L : 12D h and a constant temperature of $25^{\circ} \mathrm{C}$, time needed for the completion of diapause (48.5 d) was comparable with that under a ther- 
TABLE 1. Analysis of variance results (ANOVA), (A) for diapause incidence (\%) and (B-D) for days needed for pupation in $S$. nonagrioides larvae reared under various combinations of temperature, photoperiod, and thermoperiod.

\begin{tabular}{lcccc}
\hline Experiment & Source of variation & Df & $F^{a}$ & Data shown in \\
\hline A. Photoperiod x Cryophase & Photoperiod & 1,42 & 115.7671 & Figure 1 \\
& Cryophase & 6,42 & 62.0959 & \\
B. Temperature x Photoperiod & Photop. x Cryoph. & 6,42 & 29.6582 & Table 2 \\
& Temperature & 2,27 & 158.4205 & 179.7486 \\
C.Thermophotoperiod x Photoperiod & Photoperiod & 2,27 & 66.1892 & Table 3 \\
& Temp. x Photop. & 4,27 & 2.5350 & 19.6152 \\
D. Thermoperiod & Thermophotop. & 2,27 & 6.9303 & Table 4 \\
\hline
\end{tabular}

Data on diapause incidence (\%) of Fig. 1 were transformed using the arcsine square-root transformation before the ANOVAs were conducted.

${ }^{\mathrm{a} A l l} \mathrm{P}$ were $<0,05$

moperiod CT $12: 12\left(20^{\circ}: 30^{\circ}\right)(54 \mathrm{~d})$, in which the high temperature of the thermoperiod coincided with the scotophase of the photoperiod. In contrast, significantly more time $(77 \mathrm{~d})$ was needed for the pupation of diapausing larvae when they have been transferred to $12 \mathrm{~L}: 12 \mathrm{D} \mathrm{h}$ and a thermoperiod of $\mathrm{TC} 12: 12\left(30^{\circ}: 20^{\circ}\right)$, where the cold phase of the temperature cycle coincided with the scotophase. Hence, it seems that diapause persisted when larvae were subjected to thermoperiods where the low temperature coincided with the scotophase. The data also show that under a constant temperature of $25^{\circ} \mathrm{C}$, significantly less time was required for diapause development in continuous illumination than in continuous darkness. However, the larvae maintained in constant darkness and a thermoperiod of TC $12: 12\left(30^{\circ}: 20^{\circ}\right)$ reached pupation in less time $(54.5 \mathrm{~d})$ than those at the constant temperature of $25^{\circ} \mathrm{C}$ and DD $(70 \mathrm{~d})$.

The termination of diapause was also evaluated when diapausing larvae were exposed to thermophotoperiods of different temperature amplitudes with the same mean temperature of $25^{\circ} \mathrm{C}$ (Table 4). Days needed for pupation were significantly reduced with the decrease in the amplitude of the thermoperiod (Table 1 and 4), i.e. the higher the amplitude the longer the delay before pupation. Furthermore, the increase in temperature of the scotophase

TABLE 2. Days needed for pupation (mean $\pm \mathrm{sd}$ ) of $50 \%$ of diapausing larvae of $S$. nonagrioides after their transfer at the age of $55 \mathrm{~d}$ from $25^{\circ} \mathrm{C}$ and LD $10: 14 \mathrm{~h}$ to different temperatures $\left(25,27.5\right.$ and $\left.30^{\circ} \mathrm{C}\right)$ and different photoperiods LD 16:8, 12:12 and 10:14 h.

\begin{tabular}{lccc}
\hline & \multicolumn{3}{c}{ Temperature regimen $\left({ }^{\circ} \mathrm{C}\right)$} \\
\cline { 2 - 4 } & 25 & \multicolumn{3}{c}{27.5} & 30 \\
\cline { 2 - 4 } $\begin{array}{l}\text { Light } \\
\text { regimen }(\mathrm{h})\end{array}$ & \multicolumn{3}{c}{ Time needed for pupation (days) } \\
(mean \pm sd) \\
\hline $16 \mathrm{~L}: 8 \mathrm{D}$ & $14.81 \pm 1.74 \mathrm{a}$ & $15.45 \pm 1.21 \mathrm{a}$ & $13.75 \pm 0.78 \mathrm{a}$ \\
$12 \mathrm{~L}: 12 \mathrm{D}$ & $48.51 \pm 9.18 \mathrm{~b}$ & $31.52 \pm 3.41 \mathrm{c}$ & $12.25 \pm 2.25 \mathrm{a}$ \\
$10 \mathrm{~L}: 14 \mathrm{D}$ & $119.25 \pm 11.95 \mathrm{~d}$ & $59.00 \pm 11.51 \mathrm{e}$ & $14.51 \pm 2.08 \mathrm{a}$ \\
\hline
\end{tabular}

Values followed by the same letter are not significantly different at $P=0.05$, by LSD test, after ANOVA. (from 18 to $20^{\circ} \mathrm{C}$ ) resulted in a significant reduction in time for the completion of diapause (Table 1 and 4 ).

\section{DISCUSSION}

From the data described above, it is obvious that thermoperiod had a measurable effect on diapause induction in $S$. nonagrioides, but this effect was less pronounced than that of the thermophotoperiod (Fig.1). Furthermore, low cryoscotophase temperatures greatly modified the photoperiodic response. Cryophase temperatures lower than $10^{\circ} \mathrm{C}$ need not be evaluated since the lower thermal limit of larvae of $S$. nonagrioides is $10.85^{\circ} \mathrm{C}$ (Thanopoulos \& Tsitsipis, 1989).

Fantinou \& Kagou (2000) reported that larvae of this species were able to distinguish a long-day thermoperiod from a short-day thermoperiod inducing diapause. Consequently, the absence of any photoperiodic stimuli could start the free-running rhythm of the circadian clock. The results of the present research indicate, however, that a weaker response (diapause incidence) was demonstrated when larvae were subjected to thermoperiods in absence of light (Fig. 1). The thermophase, therefore, does not seem to function as a simple direct substitute of the photophase of the photoperiod as the two response curves differed. Therefore, this difference must be accounted for

TABle 3. Days needed for pupation (mean $\pm \mathrm{sd}$ ) of $50 \%$ of diapausing larvae of $S$. nonagrioides after their transfer at the age of $55 \mathrm{~d}$ from $25^{\circ} \mathrm{C}$ and LD $10: 14 \mathrm{~h}$ to different thermoperiodic TC $12: 12\left(25^{\circ}: 25^{\circ}, 30^{\circ}: 20^{\circ}\right)$ or CT $12: 12\left(20^{\circ}: 30^{\circ}\right)$ and lighting conditions (LD, LL and DD).

\begin{tabular}{lccc}
\hline & \multicolumn{3}{c}{ Temperature regimen $\left({ }^{\circ} \mathrm{C}\right)$} \\
\cline { 2 - 4 } & TC $12: 12$ & TC $12: 12$ & CT $12: 12$ \\
Light & $25: 25$ & $30: 20$ & $20: 30$ \\
\cline { 2 - 4 } regimen (h) & \multicolumn{3}{c}{ Time needed for pupation (days) } \\
\hline 12L : 12D & $48.51 \pm 9.18 \mathrm{ab}$ & $77.00 \pm 9.62 \mathrm{c}$ & $54.00 \pm 12.11 \mathrm{~b}$ \\
LL & $36.75 \pm 5.85 \mathrm{a}$ & $42.00 \pm 6.27 \mathrm{a}$ & - \\
DD & $70.00 \pm 9.20 \mathrm{c}$ & $54.51 \pm 9.39 \mathrm{~b}$ & - \\
\hline
\end{tabular}

Values followed by the same letter are not significantly different at $P=0.05$, by LSD test, after ANOVA. 
TABLE 4. Days needed for pupation (mean $\pm \mathrm{sd}$ ) of $50 \%$ of diapausing larvae of $S$. nonagrioides after their transfer at the age of $55 \mathrm{~d}$ from $25^{\circ} \mathrm{C}$ and LD $10: 14 \mathrm{~h}$ to different thermoperiodic (TC 12:12) conditions and a photoperiod of LD 12:2.

\begin{tabular}{cc}
\hline $\begin{array}{c}\text { Temperature regimen }\left({ }^{\circ} \mathrm{C}\right) \\
\text { TC } 12: 12\end{array}$ & $\begin{array}{c}\text { Time needed for pupation (days) } \\
\text { (mean } \pm \mathrm{sd} \text { ) }\end{array}$ \\
\hline $26: 24$ & $46.25 \pm 6.34 \mathrm{a}$ \\
$28: 22$ & $50.75 \pm 8.05 \mathrm{a}$ \\
$30: 20$ & $54.51 \pm 9.39 \mathrm{a}$ \\
$32: 18$ & $76.00 \pm 6.97 \mathrm{~b}$ \\
$34: 16$ & $92.75 \pm 10.14 \mathrm{~b}$ \\
\hline
\end{tabular}

Values followed by the same letter are not significantly different at $P=0.05$ by LSD test, after ANOVA.

by the role of the photophase. Temperatures lower than $15^{\circ} \mathrm{C}$ provided lower incidences of diapause. It seems that very low temperatures may also fall outside the effective range of the temperature-compensation mechanism or maybe they slow the mechanism. Furthermore, it must be also investigated if larvae really respond to a short or long thermoperiod and become induced to diapause, or simply accumulate temperature effects on growth and development (Beck, 1983).

The present study showed that photoperiod was the crucial factor for the termination of diapause of the $S$. nonagrioides larvae, a finding supporting results from previous research (Fantinou et al., 1998). Temperatures higher than $27.5^{\circ} \mathrm{C}$ lessen the time required for diapause development in all photoperiodic regimes tested (Table 2). These data reinforce the photoperiod - temperature interaction demonstrated in previous work (Eizaguirre et al., 1994; Fantinou et al., 1995, 1998). The roles of temperature and photoperiod therefore, seem to be synergistic in enhancing diapause development. According to Hodek \& Hodkova (1988) diapause in a large number of insects may be completed more quickly at higher temperatures even in diapause - promoting photoperiods. As the termination of diapause in $S$. nonagrioides could be achieved almost immediately by the reversal of the diapause inducing factor (photoperiod), this state of diapause is characterized an oligopause according to Mueller's classification (Mueller, 1970).

Thermoperiods and the corresponding constant temperatures exerted comparable effects on the time required for pupation, although a significant difference was recorded (Table 1 and 3). Moreover, diapause development was retarded when larvae were exposed to regimes in which the cryophase temperatures coincided with the scotophase, as reported for other insects (Chippendale et al., 1976; Rock, 1983). In $S$. nonagrioides diapause development was more rapid under LL or LD at temperatures employed, than under DD, and this difference may be related to the role of the light on diapause termination. It seems that constant darkness evoked a response to diapausing larvae treated as being under a short daylength, since the $24 \mathrm{~h}$ of scotophase is obviously above the insect's intensity light threshold. The differential response of diapausing larvae under LD or DD has also been reported by Lopez et al. (1995) and needs more investigation.

Diapause development could be intensified under thermoperiodic regimes with the progressively higher cryophase rearing temperatures even under the relatively low thermophase temperature (Table 1 and 4). These data suggest that the scotophase temperature must exceed a temperature level of ca $18^{\circ} \mathrm{C}$ to evoke developmental response. Therefore, under natural conditions, the increase in night temperatures in late winter and early spring could function as a signal in eliciting diapause development. This is ecologically meaningful because in temperate regions insects are exposed to daily photoperiods and thermoperiods, in which the long nights coincide with low temperatures.

In nature, thermoperiods are associated with and synchronized to photoperiods. Insects exhibiting facultative diapause respond to seasonal changes in the environment to both photoperiodic and thermoperiodic cues. Therefore, the synergistic role of thermo- and photoperiod on eliciting developmental responses may be extremely important as a stimulus for the preparation of insects for the winter. More studies with field experiments on thermoperiodic stimuli in relation to post diapause development and adult appearance will be necessary to better understand the seasonal occurrence and the population dynamics of this species.

\section{REFERENCES}

BECK S.D. 1982: Thermoperiodic induction of larval diapause in the European corn borer, Ostrinia nubilalis. J. Insect Physiol. 28: $273-277$.

BeCK S.D. 1983: Insect thermoperiodism. Annu. Rev. Entomol. 28: $91-108$.

Brown J.R. \& Phillips J.R. 1991: Thermoperiod effects on diapause induction in Microplitis croceipes (Cresson) (Hymenoptera: Braconidae). Environ. Entomol. 20: 1444-1466.

Chippendale G.M., Reddy A.S. \& Catt C.L. 1976: Photoperiodic and thermoperiodic interactions in the regulation of the larval diapause of Diatraea grandiosella. J. Insect Physiol. 22: $823-828$.

Cordero A., Malvar R.A., Button A., Revilla P., Velasco P. \& ORDAs A. 1998: Population dynamics and life-cycle of corn borers in South Atlantic European coast. Maydica: 43: 5-12.

Eizaguirre M., Lopez C., Asin L. \& Albajes R. 1994: Thermoperiodism, photoperiodism and sensitive stage in the diapause induction of Sesamia nonagrioides (Lepidoptera: Noctuidae). J. Insect Physiol. 40: 113-119.

Fantinou A.A., Karandinos M.G. \& Tsitsipis J.A. 1995: Diapause induction in the Sesamia nonagrioides (Lepidoptera: Noctuidae) effect of photoperiod and temperature. Environ. Entomol. 24: 1458-1466.

FANTINOU A.A., TsitsiPIs J.A. \& KARANDINOS M.G. 1996: Effects of short and long photoperiods on growth and development of Sesamia nonagrioides (Lepidoptera: Noctuidae). Environ. Entomol. 25: 1337-1343.

Fantinou A.A., Tsitsiris J.A. \& Karandinos M.G. 1998: Diapause termination in Sesamia nonagrioides (Lepidoptera: Noctuidae) under laboratory and field conditions. Environ. Entomol. 27: 58-58. 
Fantinou A.A. \& Kagou E.A. 2000: Effect of thermoperiod on diapause induction of Sesamia nonagrioides. Environ. Entomol. 29: 489-494.

Galichet P.F. 1982. Hibernation d'une population de Sesamia nonagrioides Lef. (Lep.: Noctuidae) en France meridionale. Agronomie (Paris). 2: 561-566.

Hodek I. \& HoDKova M. 1988. Multiple role of temperature during insect diapause: A review. Entomol. Exp. Appl. 49: 153-165.

Hilal A. 1977: Mise en evidence d'un etat de diapause vraie chez Sesamia nonagrioides Lef. (Lepidoptera-Noctuidae). $C$. R. Acad. Sci. Ser. D. Paris 285: 365-367.

Kalushrov P., Hodkova M. \& Hodek I. 2000. Effect of thermoperiod on diapause intensity in Pyrrhocoris apterus (Heteroptera: Pyrrhocoridae). J. Insect Physiol. 47: 55-61.

KIM Y. \& SonG W. 2000: Effect of thermoperiod and phoptoperiod on cold tolerance of Spodoptera exigua (Lepidoptera: Noctuidae). Environ. Entomol. 29: 868-873

LeClant F. 1976: Pest control methods for maize in France. Ann. Appl. Biol. 87: 237-243.

Lenga A. \& Huignard J. 1992. Effect of changes in the thermoperiod on reproductive diapause in Bruchidius atrolineatus Pic (Coleoptera: Bruchidae). Physiol. Entomol. 17: 247-254.

Lopez C., EizaguirRe M. \& Albajes R. 1995: Diapause detection and monitoring in the Mediterranean corn stalk borer. Physiol. Entomol. 20: 330-336.

Mueller H.J. 1970: Formen der Dormanz bei Insekten. Nova Acta Leopold. 35: 7-27.
Rock G.C. 1983: Thermoperiodic effects on the regulation of larval diapause in the Tufted apple budmoth (Lepidoptera: Tortricidae). Environ. Entomol. 12: 1500-1503.

Statistical Graphics. 1991: Statgrafics, version 5. Statistical Graphics, Rockville, MD.

Thanopoulos R. \& Tsitsipis J.A. 1989: Effect of temperature in the egg, larval, and nymphal stage of Sesamia nonagrioides (Lef.). In: Kalmoukos P. (eds): Proceedings B' Panhellenic Entomology Meeting. Hellenic Entomological Society, Athens, Greece, pp. 97-101.

Tsitsiris J.A. 1984: Rearing the corn borer Sesamia nonagrioides on artificial media in the laboratory. In Proceedings, XVII International Congress of Entomology, 16-26 August, Hamburg, Abstracts, p. 316

TsiTsIPIS J.A. 1990: Contribution toward the development of an integrated control method for the corn stalk borer Sesamia nonagrioides (Lef.). In: Casida J.E. (eds): Pesticides and Alternatives. Elsevier, Amsterdam, pp. 217-228.

Yamashiro C., Ando C. \& Masaki S. 1998. Thermoperiod reduces the thermal constant required for oviposition in the leaf beetle Atrachya menetriesi. Entomol. Sci. 1: 299-307.

Zaslavski V.A., Znnovieva K.B., Reznik S.Ya. \& UMarova T.YA. 1995. Effect of thermoperiod and photoperiod on the eclosion rhythm of Trichogramma evanescens. Entomol. Exper. Appl. 74: 99-104.

Received February 18, 2002; revised July 1, 2002; accepted July 21, 2002 